\title{
Augusto Frederico Schmidt e sua poética da morte
}

\section{Juliana Santos*}

\begin{abstract}
Resumo: Nesse ano de 2006, em que se comemora o centenário do nascimento de Augusto Frederico Schmidt, poeta que inaugura a segunda geração da poesia moderna, torna-se fundamental o resgate de sua produção lírica, bastante esquecida pela crítica brasileira nos últimos anos. Este trabalho é fruto de pesquisa realizada em 2004 junto ao projeto "A poesia metafísica no Brasil: percursos e modulações", coordenado pela Profa. Dra. Ana Maria Lisboa de Mello e com o apoio do CNPq. O estudo foi desenvolvido a partir do levantamento e da leitura da obra e da fortuna crítica do poeta e tendo como base os fundamentos teóricos sobre a lírica, a metafísica e o imaginário. $\mathrm{O}$ ensaio apresenta as principais características da produção poética de Schmidt, como o teor metafísico e a influência dos poetas católicos franceses, focalizando sobretudo o tema da morte, fundamental em sua composição poética.
\end{abstract}

Palavras-chave: Augusto Frederico Schmidt; lírica moderna; metafísica

\begin{abstract}
In the year in which the centennial birthday of Augusto Frederico Schmidt, poet who inaugurated the second generation of modern poetry, is celebrated, it is highly appropriated to review his lyrical works, neglected by Brazilian critics to a large extent in the last years. This paper is a result of research carried out during 2004 within the project "Metaphysical poetry in Brazil: routes and modulations", supervised by Professor Ana Maria Lisboa de Mello, Ph.D., and financed by $\mathrm{CNPq}$. The research involved a survey and reading of his works and his critical reception based on the theoretical frameworks of lyrics, metaphysics, and imagery. This essay presents the main characteristics of Schmidt's poetry, such as its metaphysical character and the influence of French catholic poets, focusing specially on the theme of death, which is central in his poetics.
\end{abstract}

Keywords: Augusto Frederico Schmidt; modern lyrics; metaphysics.

Augusto Frederico Schmidt, poeta hoje desconhecido pelo grande público, revelou-se como personalidade ímpar nas letras brasileiras. Em 1928, fez sua estréia literária com a publicação da obra Canto do Brasileiro, entusiasticamente recebida por Tristão de Athayde e por outros intelectuais da época. A obra, que se colocava diretamente contra o nacionalismo literário, a poesia-piada e a poesia do cotidiano desenvolvidos pelos primeiros modernistas, é percebida imediatamente como marco da renovação, do surgimento de uma segunda geração modernista.

Schmidt destaca-se tanto pela exploração maciça de temas metafísicos, principalmente o da morte, quanto pela marcante orientação religiosa de seus versos. Essa aproximação da poesia com a religião, visível pelo uso do texto bíblico, na época encontraria pares como

\footnotetext{
* Juliana Santos é mestre em Literatura Brasileira pela UFRGS. Seu último trabalho publicado foi "Boitempo: a recordação em Carlos Drummond de Andrade", na Revista Nau Literária n. 3, 2006.
} 
Murilo Mendes, Jorge de Lima e Vinicius de Moraes, mas, atualmente, tal característica pode ser vista como um dos principais empecilhos para a exploração dessa poesia pela crítica literária brasileira.

Schmidt logo de início revela uma biografia extremamente interessante: um homem que se acreditava incapaz para os estudos e que abandonou a escola antes de terminar o secundário; de descendência judaica, sofreu perseguições em sua infância quando viveu na Suíça; ficou órfão aos 16 anos e assim iniciou uma vida de trabalho intenso como vendedor, caixeiro-viajante e empregado de serraria; mais tarde, tornou-se o dono de uma das mais importantes editoras da época, tendo lançado autores que hoje são referência nacional como Graciliano Ramos, Vinicius de Moraes e Lúcio Cardoso. Além disso, colaborou em jornais como o Correio da Manhã e $O$ Globo; atuou como administrador de empresas e, finalmente, atuou na vida política do país, tendo sido embaixador e conselheiro financeiro no governo de Juscelino Kubitschek. Os próprios amigos de Augusto Frederico ficavam perplexos diante de sua personalidade ambígua, complexa, em que coexistiam o homem de negócios, da vida prática e o homem de um lirismo inesgotável, que transformava incansavelmente a sua sensibilidade em poemas, nos mais de 700 que escreveu ${ }^{1}$.

O presente trabalho tem então como finalidade lançar luz sobre a obra poética de Schmidt, a partir da apresentação de suas principais características, entre elas o teor metafísico e a proximidade com a lírica produzida pelos poetas católicos franceses Paul Claudel e Charles Péguy. Faremos a breve apresentação de alguns poemas, dividindo-os em quatro tendências - a salvação pela morte, o terror da morte, o enfrentamento ou a superação da morte e a aceitação da morte - procurando demonstrar a exploração exaustiva deste tema por parte do poeta brasileiro.

\section{Características formais e estéticas}

Mesmo a leitura breve de alguns poemas de Schmidt já nos revela um estilo e um ritmo bastante característicos de sua lírica: um tom declamatório, beirando o profético, com um ritmo por vezes lento e envolvente, marcado pelo uso exaustivo da repetição de sons, palavras e frases. Staiger afirma que "nem somente a música das palavras, nem somente sua significação perfazem o milagre da lírica, mas sim ambos unidos em um" (1975, p. 23-24). E é essa comunhão entre mensagem profética e ritmo lânguido, solene, provocado pelos versos

\footnotetext{
${ }^{1}$ As informações sobre a biografia do poeta foram extraídas principalmente das obras SCHMIDT (1995), TOLMAN (1976) e SCHMIDT (1975). As referências completas encontram-se ao final do artigo.
} 
longos e carregados de repetições, que vai dar origem à poesia comovente e grave de Schmidt. Junta-se a isso o tom confessional, repleto de sentimentalismo, que vai levar críticos como Mário da Silva Brito, Jon Tolman, Manuel Bandeira, entre outros, a ver no poeta traços neoromânticos.

A repetição na obra de Augusto Frederico não se dá apenas na estrutura formal, mas no plano dos temas e também no das imagens-símbolos. Schmidt vai utilizar exaustivamente imagens da tradição lírica como o mar, a noite, o pássaro, a flor, entre outros elementos naturais, como recurso poético para tratar de questões universais e complexas do ser humano, como a solidão, o amor, a angústia, o mistério ou a iminência da morte. Estes temas serão apontados pelos críticos como os mais característicos da lírica schmidtiana e vão se entrelaçar compondo aquele que consideramos o grande tema de sua lírica, o da morte.

Podemos destacar ainda, no plano formal, o uso de expressões e episódios bíblicos, o uso constante da aliteração, da assonância e da repetição de palavras e frases como recursos sonoros e a utilização maciça dos versos longos e livres, ao estilo do verset claudeliano.

\section{Influências literárias}

Alfredo Bosi (1994, p. 457) aponta como principais influências de Augusto Frederico a obra dos poetas católicos franceses Paul Claudel, La Tour du Pin e, principalmente, Charles Péguy.

Paul Claudel, reconhecido poeta e dramaturgo francês, desenvolveu uma importante teoria sobre o verso. Esta teoria parte da noção de que o verso essencial e puro deve-se formar a partir da captação do momento primeiro de tensão, em que se origina a linguagem, resultando em um ritmo natural e essencialmente humano. Esse verso estaria fundamentado em um ritmo iâmbico, considerado como o ritmo do mundo, numa concepção de poesia espontânea, sem artificialismos, em que elementos rítmicos e sonoros como a rima, a repetição ou a assonância surgiriam naturalmente, impostos pela natureza e pelo espírito (cf. LECHERBONNIER et al., 1994, p. 144/160). Tal procedimento baseia-se na noção de que há uma ligação recíproca entre a libertação da linguagem e a libertação do espírito e procura, através do ritmo natural da respiração humana, atingir um ritmo vital, cósmico.

Nesse ponto, entramos em um segundo elemento importante que vai compor o chamado verset claudeliano. O poeta, de natureza católica, acreditava que a partir do resgate desse ritmo natural, cósmico, chegaríamos a uma unidade entre duas forças convergentes, a força poética e a força religiosa. Claudel vai então unir essa concepção de ritmo poético à 
força profética, mística do texto bíblico, unindo fé e poesia num único movimento (cf. LAGARDE \& MICHARD, 1973, p. 177-182).

Schmidt, por sua vez, também parece procurar na dimensão da linguagem, da palavra poética, um contato com o plano divino, fazendo ressoar, em alguns momentos, em sua voz a Voz de Deus. Os versos longos e livres, o uso aparentemente apenas intuitivo de repetições e assonâncias, o ritmo langoroso e o tom profético aproximam o poeta brasileiro do poeta francês. Além disso, a presença do texto bíblico em alguns de seus poemas e a visão simbólica da natureza, esboçada através de imagens como a noite, a lua ou o vento, também recordam a lírica claudeliana.

Passemos agora a uma aproximação entre Schmidt e o poeta Charles Péguy, considerado por alguns críticos como a principal influência na produção poética de Augusto Frederico. Jon Tolman, crítico norte-americano, estabelece uma comparação biográfica e estilística entre esses dois poetas. Ele aponta a característica que talvez seja a mais relevante na aproximação que se faz entre eles: o estilo bíblico, baseado num esquema elaborado de repetições e estruturas paralelas.

Segundo Tolman, o que caracteriza o estilo da Bíblia é a relativa predominância de formas paralelas (1976, p. 46) e ele cita como exemplo o trecho abaixo:

E disse Deus: Faça-se a luz; e fez-se a luz.

E Deus viu que a luz era boa; e dividiu a luz das trevas.

E chamou à luz dia, e às trevas noite; e da tarde e da manhã se fez o primeiro dia.

(Gênese 1: 3-5)

Tanto nos versos de Schmidt como nos de Péguy, observa-se a predominância de estruturas paralelas, tanto binárias quanto terciárias, como podemos verificar nos exemplos abaixo $^{2}$ :

Vive e palpita,/ sente e sofre (Schmidt, p. 40)

Carnal, espiritual/ temporal, eterno ${ }^{3}$ (Péguy, p. 43)

Amanhece./ Amanhece devagar./ Chuvoso o céu (Schmidt, p. 41)

Tu que apaziguas,/ tu que embalsamas,/ tu que consolas ${ }^{4}$. (Péguy, p. 43)

\footnotetext{
${ }^{2}$ Os exemplos ilustrativos da aproximação estilística entre Schmidt e Péguy foram extraídos de TOLMAN (1976). Nesta seção do ensaio serão indicados somente o poeta e a página referente à edição de Tolman.

${ }^{3}$ Tradução nossa. No original: Charnelle, spirituelle/ Temporelle, éternelle (PÉGUY apud TOLMAN, 1976, p. 43)

${ }^{4}$ Tradução nossa. No original: Toi qui apaises,/ toi qui embaumes,/ toi qui consoles. (PÉGUY apud TOLMAN, 1976, p. 43)
} 
Além disso, outros recursos que caracterizam o estilo bíblico, e que encontramos nos dois poetas, são a exergasia, ou seja, o uso sistemático de estruturas sinonímicas, e a redundância (TOLMAN, 1976, p. 47/51) ${ }^{5}$.

Alfredo Bosi (1994) indica ainda mais um poeta católico francês a exercer influência sobre a obra de Schmidt: Patrice de La Tour du Pin. No entanto, é importante destacar que o poeta francês fez sua primeira publicação em 1933, quando Schmidt já havia publicado cinco livros e já apresentava o estilo poético que perdurou até o final de sua produção. Dessa forma, a proximidade entre essas duas produções líricas não apresenta a mesma relevância e configuração que a relação que se estabelece entre a obra de Schmidt e as de Claudel e Péguy.

\section{Augusto Frederico Schmidt e a construção de uma estética da morte}

A tentativa de cercar, de penetrar o mistério da morte não se colocará na lírica schmidtiana de forma ordenada e objetiva, seguindo um percurso evolutivo no decorrer de suas publicações. A aproximação e o desenvolvimento desse tema da morte surgirão de forma complexa e desordenada, num jogo de ir e vir, em que o poeta propõe diferentes representações para o problema, sugerindo alguns caminhos de superação para essa questão, mas logo retornando à idéia de impossibilidade de certezas e soluções.

Dessa forma, parece-nos mais conveniente a apresentação dessa poética a partir da exploração dos diversos posicionamentos em relação à morte, sem considerar a sua localização dentro das obras. Cabe salientar que cada obra apresenta esses diferentes posicionamentos, mesmo parecendo contraditórios, conflitantes.

\section{A salvação pela morte}

O sentimento de inconformidade com o mundo, com a vida solitária e infeliz será muitas vezes a origem de um desejo de fuga, de evasão expressa pelo eu-lírico. A partir dos versos abaixo, extraídos do poema "Libertação", podemos perceber essa inconformidade e o anseio pela partida. A morte revela-se como caminho de libertação para o eu-lírico, que dialoga com o Senhor, pedindo que o leve e afirmando não ter raízes fundas que o prendam nessas terras, dessa vez, numa alusão ao mundo terrestre e à própria vida:

\footnotetext{
${ }^{5}$ Foram apresentadas algumas das semelhanças mais relevantes na aproximação entre a poesia de Charles Péguy e Augusto Frederico Schmidt. No entanto, como a leitura comparativa entre os poetas não se propõe como objetivo desse trabalho, a leitura da obra de Jon Tolman pode oferecer dados mais detalhados a esse respeito.
} 
$\underline{\text { Libertação }}$

Abandonaria os meus tristes e inúteis livros,

Abandonaria o meu quarto,

Abandonaria a minha casa,

$[\ldots]$

Como uma grande criança eu te seguiria, Senhor.

Eu iria contigo, se te lembrasses de passar ao alcance dos meus olhos.

Iria contigo para outros países.

Iria contigo para outros contatos.

Porque as raízes que me prendem aqui não são fundas,

Sou como o arbusto tenro que o vento arranca do seio da terra.

Eu iria contigo, Senhor!

E minha partida seria uma infinita libertação.

[...]

$\left(\right.$ SCHMIDT, 1995, p. 106-107) ${ }^{6}$

Essa consciência de inutilidade de todas as coisas e da própria vida indica-nos que esse desejo de morte está ligado, em alguns momentos, à idéia de libertar-se de um mundo de sofrimento e de desilusão e desse sentimento de incerteza que aflige o homem. No entanto, o reino dos mortos não parece significar um lugar benéfico por si mesmo, sugere apenas uma possibilidade de fuga.

No próximo poema, o eu-lírico também se coloca ansioso pelo fim de sua existência e, mais uma vez, a morte vai significar primordialmente uma ruptura e uma anulação do ser e não uma forma de salvação. Podemos perceber isso através das imagens que são atribuídas à condição de morto, como "silêncio e frio apenas", "íntimo da terra" ou "mudado em poeira", através da caracterização da morte como "vento frio" e da exploração de um espaço dominado por túmulos e "Cristos de gelo". Vejamos:

$\underline{\text { Paz dos túmulos }}$

[...]

Ó mármores gelados, rosas frias, Cristos de gelo, como vos espero!

Quando serei silêncio e frio apenas?

Quando serei apenas o íntimo da terra?

Quando, enfim, dormirei na paz - na álgida paz?

Ó vento que matais as rosas, vento frio!

Quando me levareis mudado em poeira?

[...]

(p. 178)

\section{0 terror da morte}

Nos poemas analisados anteriomente, pudemos perceber que a morte, em alguns momentos, era vista enquanto um fim em si mesma, uma simples anulação do ser ou um mero

\footnotetext{
${ }^{6}$ Todos os poemas foram extraídos da obra SCHMIDT (1995). A partir daqui, serão referidas apenas as páginas.
} 
caminho de fuga da condição terrena. Essas idéias vão de encontro à tradição cristã, que propõe a morte como momento de "encontro com Deus" ou "descanso eterno". Nesta seção, observaremos uma perspectiva expressamente contrária aos preceitos católicos de morte, à medida que o eu-lírico vai questionar e mesmo negar a idéia de morte como salvação ou espaço sagrado, positivo.

Nos versos abaixo, podemos perceber o diálogo que o eu-lírico trava com Deus a respeito da morte e apresenta a sua angústia, a sua incerteza diante do momento derradeiro:

\section{$\underline{\text { Pensamento noturno }}$}

\section{$[\ldots]$}

Meu Deus, a tua noite será assim tranqüila e escura,

Como esta noite cheia de paz e de esquecimento?

Será simples - e para dormir apenas - a tua noite ó meu Deus?

Ou ficaremos nela, acordados, ouvindo gritos no escuro,

Sentindo os grandes frios, e vendo as terríveis luzes que te cercam?

Dizei-nos, Senhor: a tua noite é para dormir profundamente, como esta noite?

(p. 246-247)

No poema a seguir, podemos perceber as tintas negras e o toque trágico com que Schmidt pinta a imagem da morte, contrastando imensamente com a visão redentora e iluminada pregada pelo catolicismo. O poema traz a imagem do vento, gelado e repentino, para indiciar a morte. Além disso, o pássaro morto está com as asas em cruz, remetendo à tragédia da crucificação de Cristo. Vejamos:

\section{$\underline{\text { Poema }}$}

Era um grande pássaro. As asas estavam em cruz, abertas para os céus.

A morte, súbita, o teria precipitado nas areias molhadas.

Estaria de viagem, em demanda de outros céus mais frios!

Era um grande pássaro, que a morte asperamente dominara.

Era um grande e escuro pássaro, que o gelado e repentino vento sufocara.

Chovia na hora em que o contemplei.

Era alguma coisa de trágico,

Tão escuro, e tão misterioso, naquele ermo.

Era alguma coisa de trágico. As asas, que os azuis queimaram,

Pareciam uma cruz aberta no úmido areal.

O grande bico aberto guardava um grito perdido e terrível.

(p. 191)

\section{Onfrentamento ou a superação da morte}

Schmidt, ao explorar sob diversos ângulos a problemática da morte, lançou em seus poemas algumas pistas, e mesmo algumas respostas, para abrandar a angústia inerente à condição mortal do homem. Entre elas estão a salvação através da paternidade e da memória 
dos que ficam, através da fé e da idéia de ressurreição, ou ainda a salvação por meio do amor, da poesia e do contato com a natureza.

Apresentamos, como exemplo desta tendência, apenas um poema. Nele, podemos perceber a presença de Deus como forma de superar a angústia e o medo da morte. Temos um dos raros momentos em que o eu-lírico parece encontrar sentido em sua existência. Os versos sugerem um agradecimento pelo sopro de vida que ele sente vibrar ao integrar-se ao mundo natural. O momento de harmonia com a natureza revela-se como um encontro com o próprio plano divino:

$\underline{\text { Poema }}$

Quantos ninhos nas árvores,

Quantas flores!

A leve, a clara, a doce alegria da primavera

Sufoca as últimas resistências,

As últimas seduções da morte,

Os últimos convites à tristeza e ao desalento.

Sinto a tua presença nas coisas,

Sinto o teu olhar sobre o tempo,

O teu olhar viajando pelo céu lúcido, Acariciando as árvores, Transformando o mundo, Fazendo o mundo à tua imagem.

Sinto que és a primavera.

Estão nascendo flores inesperadas,

As árvores ficaram cheias de ninhos,

Tudo porque despertaste para o meu conhecimento

E a tua música,

A tua luz,

E os teus cabelos,

Me foram de repente revelados!

(p. 338)

\section{A aceitação da morte}

Seguindo essa tendência, temos alguns poemas escritos por Schmidt, já no período final de sua produção, que apresentam uma nota de resignação, uma espécie de desistência por parte do eu-lírico em tentar aproximar-se do mistério que cerca a morte e solucioná-lo. A tentativa de explorar todas as faces da morte chega ao final com uma feição nova para o tema, mas essa nova perspectiva diante da morte não estará isolada, mas sim ainda rodeada das faces já desenhadas durante todo o percurso poético.

$\mathrm{O}$ poema abaixo traz consigo uma aceitação tranqüila para a morte que se aproxima. $\mathrm{O}$ eu-lírico parece conformar-se com o mistério que envolve o desconhecido e vê a morte como 
um momento de passagem, de conversão, em que a flor se converterá em fruto. Não é mais um fim absoluto como pudemos ver em outros versos:

\section{$\underline{\text { Aurora lívida }}$}

Em mim a flor da morte

Em fruto se converte.

[...]

Dentro em pouco serei forma e passado,

Não mais palpitação e inquieta chama.

\section{$[\ldots]$}

Em mim a flor da morte

Em fruto amadurece

E vou me despedindo

Deste reino da terra,

Tão cheio de mistérios e surpresas.

Todo o meu ser se acalma,

Sinto que será bom dormir.

[...]

(p. 537)

No próximo poema, o eu-lírico afirma o desespero que sente, mas não quer que essa dor passe para a sua canção, numa tentativa de não sentir o pavor que o assola diante da morte...

\section{Desejo de escrever uma canção}

Desejo de escrever uma canção

De adeus ao mundo.

Uma canção sem desespero,

Uma canção tranqüila

Em que toda a tristeza de partir

Pela virtude musical se transmudasse

Numa espécie de alegria dolorosa!

\section{$[\ldots]$}

Desejo de cantar

$\mathrm{O}$ adeus ao mundo

Exaltando as belas coisas

E altas horas vividas.

\section{$[\ldots]$}

Desejo de dizer adeus ao que sou

E ao que fui,

Numa bela e clara canção

Sem desespero.

(p. 596-597)

Esse modo labiríntico de ir e vir com que Schmidt aproxima-se das questões de ordem metafísica, principalmente no que tange ao problema da condição mortal do homem, e que pudemos observar a partir dos poemas analisados neste artigo, nos faz vislumbrar a 
impossibilidade de se chegar a uma solução final para tal impasse. O poeta faz aproximações do problema da morte e sugere, em alguns momentos, a fé, a busca de Deus como forma de salvação ou de atenuação do sofrimento. No entanto, a própria impossibilidade de "crer longamente"7, expressa por vezes pelo eu-lírico, e a insolubilidade do mistério da morte fazem com que não se chegue a uma resolução final. Dessa forma, o caráter religioso da poesia produzida por Augusto Frederico Schmidt não se coloca de forma alguma como limitador ou doutrinário, e sim como caminho de reflexão, de prazer estético e como forma de promover ao leitor um reencontro consigo mesmo, valores esses fundamentais para se fazer boa poesia.

\section{Referências}

BOSI, Alfredo. História Concisa da Literatura Brasileira. 41ª ed. São Paulo: Cultrix, 1994.

LAGARDE, André; MICHARD, Laurent. XXe Siècle. VI. Paris: Bordas, 1973.

LECHERBONNIER, Bernard; BRUNEL, Pierre; RINCE, Dominique; MOATTI, Christiane. Littérature - textes et documents. XXe. Siècle. Collection dirigée par Hemri Mitterand; avec la collaboration de Olivier Barabarant...[et al.]. Paris: Nathan, 1994.

SCHMIDT, Augusto Frederico. Eu te direi as grandes palavras: poemas escolhidos e versos inéditos. Organizado por Alphonsus de Guimaraens Filho. Rio de Janeiro: José Aguilar, 1975.

Poesia completa: 1928-1965. Introdução de Gilberto Mendonça Teles. Rio de Janeiro: Topbooks / Faculdade da Cidade, 1995.

STAIGER, Emil. O estilo lírico. In: . Conceitos fundamentais da poética. Rio de Janeiro: Tempo Brasileiro, 1975.

TOLMAN, Jon M.. Augusto Frederico Schmidt: estudo crítico. Tradução de Laís Corrêa de Araújo. São Paulo: Quíron; Brasília: INL, 1976.

\footnotetext{
${ }^{7}$ Expressão retirada do poema "Visita à casa materna" (p. 531).
} 